\title{
EL CULTIVO DEL MIJO, (PANICUM MILIACEUM, L.), EN LA CULTURA CASTREÑA DEL NOROESTE DE LA PENÍNSULA IBÉRICA
}

\author{
por \\ J.M. VÁZQUEZ VARELA
}

Se presenta una interpretación del papel del cultivo del mijo, Panicum miliaceum $L$., en la cultura castreña del Noroeste de la Península Ibérica, basada en un estudio etnoarqueológico reciente sobre esta planta en Galicia (Vázquez, J. 1994).

De acuerdo con el modelo etnográfico es posible conocer con detalle aspectos cruciales, relativos a su uso, y a las consecuencias derivadas del mismo en el mundo castreño.

Según los datos paleobotánicos, de Galicia y otras zonas del norte de España, este cereal hace su aparición, de un modo generalizado, en el momento de la transición del Bronce final a la Primera la Edad del Hierro (Cubero, C. 1991), (Maya, J.L. 1992).

En Galicia se encuentra presente en varios yacimientos castreños, tanto en la costa como del interior, desde los más antiguos hasta los de cronología reciente, en los que también aparecen otros cereales como el trigo y la cebada, aunque ésta en menor medida, y frutos, sobre todo bellotas. En Portugal también aparece bien documentado (Ramil, P. 1993 a y b).

\section{EL MODELO ETNOARQUEOLÓGICO}

El trabajo de campo se realizó en los ayuntamientos de Negreira y Outes, en el occidente de la provincia de A Coruña, donde aún una familia

"CUADERNOS DE ESTUdiOS GALLEGOS", Tomo XLI, Fascículo 106, Santiago 1993-94. 
campesina cultiva el mijo, que hasta hace cuarenta años ha tenido cierto papel en la agricultura de la comarca.

Sus rasgos fundamentales son los siguientes:

\section{El cultivo}

Actualmente este cereal forma parte de las siguientes rotaciones:

Trigo - Mijo - Hierba

Trigo - Mijo - Descanso

Centeno - Mijo - Hierba

Centeno - Mijo - Descanso

Centeno - Mijo - Nabos - Maiz - Patatas

El cultivo siempre se realiza en las tierras de labor, más o menos próximas a la casa, donde se daban trigo, centeno, maiz, hierba, nabos y patatas, y nunca en el monte donde ocasionalmente se echaba centeno y trigo.

Se siembra desde fines de junio a mediados o finales de julio, lo más frecuente sobre el día 10.

Cogido el centeno o el trigo de la finca, se llevaba a ella el estiércol de las cuadras en un carro de vacas y se distribuía en pequeños montones. Actualmente no se emplea ningún tipo de abonado. Una vez recogido el trigo o el centeno se pasaba al arado de palo por la tierra para removerla, y después la grada para deshacer los terrones y allanarla.

Se siembra espeso, a voleo, a puñados, con un movimiento circular rápido, en el que se abre la mano poco a poco, del mismo modo que se hace para el trigo o el centeno. Esta labor se realiza por hombres o por mujeres indistintamente, quienes avanzan por los surcos sacando las semillas de una bolsa, una cesta o un cubo. Después se pasaba una grada para protegerlas.

Debido a que se siembra en una época en que la tierra está seca se suele hacer la faena al atardecer.

Una vez sembrado no requiere ningún tipo de cuidado tales como aclarado, extracción de malas hierbas, remoción del terreno, o protección contra las plagas, o contra los pájaros, ya que no se utilizan los espantapájaros.

Se recoge a fines de Septiembre, hacia el día de San Miguel, el 29, cuando el grano se pone amarillo lo cual indica que alcanzó su madurez.

Según los informantes, a menudo, en los últimos años se sembraba y recogía fuera de la época tradicional, dado su escaso interés económico y facilidad de adaptación, por lo que no era infrecuente que, intercalado con rotaciones distintas a las más tradicionales, se sembrase a mediados de 
agosto y se segase a mediados de octubre, sin ningún tipo de cuidado y en tierras a veces muy marginales. El desinterés llegó a tal extremo, que cuentan que algunas veces, cuando la cosecha era tardía y poco valiosa, no se segaba y se dejaba intacta en la finca hasta el año siguiente.

La planta es de desarrollo rápido, a la semana o diez días de la siembra se ve como sale el tallo de la tierra. A lo largo del proceso de maduración el grano va cambiando del color verde al amarillo que es el indicativo de la madurez.

\section{La siega}

Se usa una hoz pequeña con la que se cortan las plantas a ras de tierra, en lotes. Con una mano se cogen varios tallos, y se cortan de un golpe. Una vez cortadas se colocan en montones, que se atan con otras plantas para facilitar su transporte al carro.

La siega es una labor comunitaria, en la que intervienen los miembros de la casa, familiares, y vecinos a los que a su vez se les devuelve el trabajo aportado, cuando tienen que recoger su propia cosecha.

Algunos informantes nos dijeron que cogían con una mano la parte superior de las plantas y segaban los tallos a mediana altura, no como en el caso anterior en que se hacía lo más próximo posible a la raiz. Quizás esta variante se debe a que al ser en los últimos tiempos un cultivo marginal, con un valor económico casi anecdótico, se hacía la operación lo más cómoda posible desperdiciando la paja, que ya en esta época tenía poco valor, mucho menor que el tradicional, que nunca fue grande como se puede ver en el apartado de usos.

La mies segada se cargaba en carros de vacas y se trasladaban a la era de las casas. Durante este proceso comenzaba en el carro un proceso de fermentación, conocido como "arder", en el que la planta se calentaba y desprendía algo de humo blanco.

\section{La trilla}

Con el mayal, al igual que otros cereales tales como el trigo y el centeno. Una vez colocadas las plantas, en circulo, con las espigas tocándose, se golpeaba con el extremo del palo móvil sobre la espiga.

\section{Con horquilla}

En el caso de que hubiese que trillar solamente un pequeña cantidad se golpeaba con fuerza con una horquilla de madera. 


\section{A mano}

En algunos casos, cuando la cantidad era realmente muy pequeña, se cogían a mano las plantas y se golpeaban las espigas con fuerza contra una piedra.

Algunos informantes aseguran que la fermentación del mijo permite trillarlo más comodamente pero que imposibilita, por su sabor ácido, su empleo para hacer pan.

Una vez trilladas las plantas se sacuden a mano los pequeños manojos de modo que los granos, que han quedado retenidos en la espiga, o entre los tallos, se desprendan y caigan al suelo.

\section{La limpieza}

Concluida la operación anterior, se recogía la paja con horquillas o rastrillos, con los dientes más próximos entre sí que los que se emplean actualmente en las faenas de la hierba. Su destino final era alimentar a las vacas o para hacer estiércol mezclada con el tojo.

El grano se recogía con rastrillos para proceder a su limpieza, en la que se usaba una criba para separar el grano de las sustancias acompañantes, paja, hojas, etc., y se colocaba a secar en un lugar soleado. Días más tarde se llevaba al exterior a un lugar ventoso, donde se hacía saltar repetidamente sobre la criba o un recipiente, sobre una manta de modo que el aire se llevara los restos de la paja y del polvo que hubiesen quedado del proceso anterior.

En algunas zonas con ayuda de la criba se separaban los granos más pequeños, con destino a las aves de corral, de los más grandes, que también pueden servir para ellas o para la alimentación humana.

En otras aldeas no se separa el grano grande del pequeño y sólo lo limpiaban aventándolo, para que se fuesen las impurezas.

\section{Conservación}

Se guardaba en una artesa o arca de madera en la casa, en un rincón de un almacén, o en sacos en la parte superior de la cuadra. En este caso no se podían colocar unos sobre otros, pues esto producía su fermentación, lo cual le hacía perder la capacidad reproductiva.

\section{Usos}

El cereal se sembraba para ser utilizado como fuente de grano con destino a la alimentación humana y animal. La paja se reservaba para éstos.

"CuAdERnOS DE ESTUdios GAlLEGOS", Tomo XLI, Fascículo 106, Santiago 1993-94. 
El grano:

1. Alimento para los animales. Se emplea en forma de harina para los cerdos y vacas, pero sobre todo para las gallinas, especialmente para los polluelos, en grano, pues se considera que gracias a su consumo se pueden obtener cantidad y calidad en los huevos, incluso mejor que el maiz o el salvado.

2. Alimento para los humanos:

A. Gachas. En forma de gachas, "papas", que solían tomarse en el desayuno y en la cena. Se preparaban poniendo leche a calentar en una tartera, cuando empezaba a hervir se echaba la harina poco a poco revolviéndola con una cuchara de palo hasta que las papas alcanzaban su punto.

Recuerdan los comunicantes su sabor ácido y que, a veces, había en ellas pequeños grumos, que daban la sensación de ser pequeñas arenillas, que a veces rascaban en la boca, quizás debido a las dificultades de moler en los molinos de agua, dedicados al trigo y al maiz, un cereal de grano redondo, pequeño y duro.

B. Pan. La harina de mijo se escaldaba en agua hirviendo, y después de mezclada con centeno o trigo, se hacían bolas o pan en el horno doméstico.

En alguna zona había la creencia de que su consumo fomentaba la producción de la leche en las vacas.

La paja:

Se empleaba directamente en verde para la alimentación del ganado, por el cual era muy apreciada, o se formaban pajares para mantenerla seca y disponible para las necesidades del invierno.

Algunos informantes dicen que si el mijo fermentó mucho, en el proceso de almacenamiento previo a la maja, la paja no vale pues el ganado la come con dificultad. En este caso se echa en la cuadra para producir estiércol destinado al abonado de las fincas.

\section{Rendimiento}

Debido al tiempo transcurrido desde la desaparición del cultivo en muchas de las zonas, a su carácter marginal al que no se le prestaba la misma atención detenida que a otros más importantes, y a que las comunidades domésticas campesinas no son empresas capitalistas de estricta contabilidad, y en las que el "a ojo" tiene bastante peso en las operaciones, resulta muy difícil precisar los rendimientos.

La dificultad aumenta hasta el punto de que muy poca gente sabe cual

"CUADERNOS DE ESTUdIOS GALLEGOS", Tomo XLI, Fascículo 106, Santiago 1993-94. 
era el valor absoluto de la unidad de medida de la semilla sembrada, el ferrado, pues distintas personas que lo cultivaron, o que lo vieron hacer no recordaban la cifra o daban números distintos. Para solventar esta dificultad en la medida de lo posible exponemos los datos, desde los más genéricos hasta los más concretos.

Para la totalidad de los encuestados la planta daba mucho, y esto era muy apreciado por cuanto no exigía ningún cuidado desde la siembra hasta la maja. Incluso reconocían que si se echasen en buena tierra y se abonasen convenientemente producirían mucho más.

Había años de mucha cosecha y otros de ninguna debido fundamentalmente a la climatología. Se piensa que con buena humedad es mayor la cosecha que con la sequía, que da granos más pequeños y duros.

Según los últimos cultivadores, un ferrado de sembradura, medida de superficie, tiene en aquella zona 528 metros cuadrados, y uno de semilla de mijo un peso de 16 kilogramos. La siembra de un ferrado de semilla requiere una superficie de 5 de sembradura, 2.640 metros cuadrados. Un ferrado de semilla sembrada en la superficie citada, puede dar de cosecha óptima hasta setenta ferrados de grano, lo que supone un rendimiento aproximado de $40 \mathrm{Hl} / \mathrm{Ha}$, cifra que parece muy elevada en relación con el promedio habitual de las cosechas, según otros informantes, quienes estiman que ronda los $28 \mathrm{Hl} / \mathrm{Ha}$. Esta última cantidad es parecida a los rendimientos del trigo y del centeno en la zona.

\section{LA APLICACIÓN DEL MODELO ETNOARQUEOLÓGICO}

Del modelo etnoarqueológico son destacables una serie de rasgos, de gran interés para entender su función en la agricultura castreña:

Versatilidad, se adapta a muy diferentes suelos y climas.

Rendimiento, equivalente al del trigo y el centeno.

Brevedad y elasticidad de su ciclo, en dos meses ha madurado y se puede sembrar lo mismo a fines de junio que a mediados de agosto, y recogerse a mediados de septiembre que de octubre.

Gran capacidad de entrar en rotaciones de cultivos.

Multiplicidad de usos pues vale tanto para personas, es panificable, como para animales.

Aprovechamiento integral.

Requiere pocos cuidados, sin abonos, ni faenas desde la siembra hasta la cosecha.

"CUADERNOS DE ESTUDIOS GALLEGOS", Tomo XLI, Fascículo 106, Santiago 1993-94. 
Otros rasgos positivos, también de gran importancia, son facilidad de recolección y maja, así como de conservación del grano,y su gran poder germinativo.

Todas estas series de características lo hacen apetecible en cualquier agricultura, y encajan muy bien dentro de la castreña. En ésta prodría rotar con el trigo y la cebada en la misma finca, del siguiente modo:

1.- Siembra del trigo en invierno o en primavera, siega del mismo en julio, y a continuación cultivo a del mijo que se podría, recolectar en septiembre u octubre. Después descanso.

2.- Siembra de la cebada en invierno o primavera, que se recogería en verano, y después los dos meses de cultivo del mijo seguidos de un período de descanso.

Estas posibilidades suponen duplicar la cosecha en la misma finca, con la importancia que ello encierra para la subsistencia, además con un cultivo que requiere mínima inversión de energía y tiempo.

La diversificación de las cosechas supone una disminución del riesgo en el proceso productivo, pues las causas de una mala cosecha del trigo o la cebada, sembradas en invierno o en primavera, no tienen porque afectar al mijo.

La presencia de esta planta en un cierto número de yacimientos, cuando los estudios paleobotánicos están aún en su fase inicial, acompañado de otros cereales, el trigo es el más abundante, es un claro testimonio de que los castreños apreciaron la comodidad y restabilidad de su cultivo.

Este permite disponer de un alimento, en forma de pan o de gachas, para los humanos y de harina y paja para los animales. También hay datos etnográficos de Bulgaria (Renfrew, J. 1973) que permiten pensar en su uso para fabricar una bebida alcohólica.

La aparición del mijo en alguno de los castros más antiguos de Galicia, como Penalba con un conjunto de dataciones en el siglo VI a.C., carbono catorce sin calibrar (Aira, Mª.; Ramil, P. y Álvarez, A. 1990), nos inclinan a pensar que pudo haber sido un factor de cierta importancia en el nacimiento de la cultura castreña. Su presencia en este mundo permite duplicar las cosechas en el mismo terreno con muy poco esfuerzo, lo que supone un notable aumento del valor de la producción agrícola, y por tanto de las tierras susceptibles de cultivo fácil. Una base cerealística productiva es una circunstancia que favorece el aumento de la población, lo que a su vez origina una mayor demanda de las tierras de cultivo, y el aumento de su valor.

El desarrollo de algunos de los primeros castros, que suponen una po-

"CUADERNOS DE ESTUDIOS GALLEGOS", Tomo XLI, Fascículo 106, Santiago 1993-94. 
blación, muy posiblemente, plenamente sedentaria, con ocupaciones muy duraderas en un mismo punto del paisaje, que implican un nuevo tipo de control del territorio, no es ajeno a las facilidades que otorga este cereal, hasta ahora ausente de la región, quizás de un modo total, o en todo caso de un modo significativo.

El crecimiento demográfico, y la nueva importancia que se da a territorios productivos concretos, factores que se pueden considerar implicados con el inicio del mundo castreño del noroeste, pueden estar perfectamente relacionados con el cultivo del mijo, pues éste facilita ambos.

La presencia del mijo en la agricultura castreña, a lo largo de todas sus fases, ha permitido una producción capaz de sostener el notable desarrollo demográfico de la cultura de los castros, a lo largo de su historia.

La presencia conjunta, en las excavaciones arqueológicas, de paleobotánicos o arqueobotánicos, y arqueólogos, así como la de todos ellos, y de los etnoarqueólogos, en los laboratorios, permitirá disponer de más información precisa, necesaria para la contrastación, y quizás desarrollo de la hipótesis, aquí esbozada, de la importancia del mijo en el nacimiento y evolución del mundo castreño.

\section{BIBLIOGRAFÍA}

AIRA RODRÍGUEZ, M J., RAMIL REGO, P. y ÁLVAREZ NÚÑEZ, A., 1990. Estudio paleocarpológico realizado en el Castro de Penalba (Campolameiro, Pontevedra. España). Botánica complutensis 16: 8189.

CUBERO CORPAS, C., 1991. Panicum miliaceum en la Edad del Hierro en el Noroeste de la Península Ibérica. Paleoecología \& Arqueología II. Vila Nova de Famaliçao.

MAYA GONZÁLEZ, J.L., 1992. Aprovechamiento del medio y paleoeconomía durante las etapas metalúrgicas del Noroeste Peninsular, en MOURE ROMANILLO, A. (Ed): Elefantes, Ciervos y Ovicaprinos. Economía y aprovechamiento del medio en la Prehistoria de España y Portugal. Universidad de Cantabria. Santander.

RAMIL REGO, P., 1993a. Paleoethnobotánica de yacimientos arqueológicos holocenos de Galicia. (N.O. Cantábrico), Munibe, 45: 165-174.

"CUAdERNOS DE eStudios GAlLEGOS", Tomo XLI, Fascículo 106, Santiago 1993-94. 
1993b. Evolución climática e historia de la vegetación durante el Pleistoceno Superior y el Holoceno en las regiones montañosas del Noroeste Ibérico, en PÉREZ, A., GUITÁN, L. y RAMIL, P. (Eds). La evolución del paisaje en las montañas del entorno de los caminos jacobeos. Xunta de Galicia. Santiago.

RENFREW, J. 1973, Paleoethnobotany. The prehistoric foods plants of the Near East and Europe. Methuen. London.

VÁZQUEZ VARELA, J.M., 1994. El cultivo tradicional del millo miudo (Panicum miliaceum L.) en Galicia. Ponencia presentada en el Simposio Internacional in Memoriam de Xaquín Lorenzo. Tecnoloxía Tradicional. Dimensión Patrimonial. ,Valoración Antropolóxica. 13-15 Outubro, 1994. Ourense (En prensa.) 